GU J Sci, Part C, 5(4): 47-58 (2017)

Gazi Üniversitesi
Fen Bilimleri Dergisi
PART C: TASARIM VE TEKNOLOJI
dergipark.gov.tr/http-gujsc-gazi-edu-tr

\title{
Kablosuz kontrol amaciyla geliştirilmiş bir proses kontrol simülatöründe sistem dinamiğinin teorik ve deneysel incelenmesi
}

\author{
İsmail BAYRAM* \\ Ahi Evran Üniversitesi, Mühendislik-Mimarlık Fakültesi, Kimya ve Proses Mühendisliği Bölümü, Kırşehir/TÜRKIYYE
}

\begin{abstract}
$\ddot{\text { Öz }}$
Makale Bilgisi

Başvuru: 20/03/2017

Düzeltme: 25/07/2017

Kabul: 20/09/2017

Anahtar Kelimeler

Sistem dinamiği MATLAB Sistem tanımlama,

ARIMAX model

Keywords

Sistem tanımlama, proses kontrol çalışmalarının başarısını etkileyen oldukça önemli bir işlemdir. Sistem tanımlama için kablosuz proses kontrol simülatöründe deneysel ve MATLAB kullanımıyla teorik çalışmalar yapılmıştır. Kablosuz sıvı seviye deneylerinde öncelikle yatışkın hal deneyleri gerçekleştirilmiştir. Sistem dinamiğini incelemek amacıyla sıvı seviye vana açıklığına basamak, PRBS ve kare dalga etkiler verilerek sıvı seviyesinin zamanla değişimi gözlenmiştir. Böylelikle açık hat dinamik deneyler gerçekleştirilerek sistemin özellikleri belirlenmiştir. Proses kontrol simulatörünün sıvı seviyesiyle, sıvı seviye kontrol vanası açıklığ 1 arasındaki ilişkiyi verecek modelin bulunması için, farklı giriş sinyalleri (basamak etki, PRBS, kar dalga) uygulanarak sistem tanımlama yapılmıştır. Dinamik hal deneylerinde başlangıçta \%10 vana açıklığında 100 s çalışılarak sistemin yatışkın hale gelmesi beklenmiş, daha sonra sıvı seviye kontrol vanasına pozitif ve negatif etkiler verilerek deneyler gerçekleştirilmiştir. Sistem tanımlama deneylerinde sistemin birinci mertebeden ölü zamanlı modele sahip olduğu varsayılmıştır. Sistem tanımlama için sıvı seviye vanasına verilen etkiler (\%10-\%65) sonucu elde edilen çıkış değişkeni verileri kullanılmıştır. Bu amaçla giriş ve çıkış değişkenlerinin değerleri MATLAB 'Sistem tanımlama araç kutusu'na işlenerek ARIMAX model katsayıları ( $a_{1}, a_{2}, b_{0}, b_{1}$, $\mathrm{b}_{2}, \mathrm{c}_{1}$ ve $\mathrm{c}_{2}$ ) belirlenmiştir.
\end{abstract}

System dynamics, MATLAB system identification, ARIMAX model

\section{Teorical and experimental investigation of system dynamics in a process control simulator developed with wireless control purpose}

\begin{abstract}
System identification is a very important process that affects the success of process control operations. For the system identification, the theoretical studies have been done by using experimental and MATLAB in the wireless process control simulator. First of all, steady state experiments were carried out in wireless liquid level tests. To investigate system dynamics, the liquid level was observed to change with time by step, PRBS and square wave effect on the liquid level valve openning. Therefore, open loop dynamic experiments were carried out to identify system spesifications. In order to determine correlation and to find the suitable model equation between liquid level and liquid level valve, system identification was done for diffrent input signals (step effect, PRBS and vawe square). In the dynamics state experiments, after the system was worked in steady state during 100 minutes when the valve is $\% 10$ open, positive and negative effects were given to the liquid level control valve. It was assumed that the system had a firstorder dead-time model in the system identification experiments. Output varaible datas obtained from the results of the effect given to the liquid level valve was used for the systen identification . Input and output datas were handled in to the 'MATLAB System Identification Toolbox' and then ARIMAX model coefficients $\left(a_{1}, a_{2}, b_{0}, b_{1}, b_{2}, c_{1}\right.$ ve $\left.c_{2}\right)$ were determined.
\end{abstract}

\section{GİRIŞ (INTRODUCTION)}

Kablosuz iletişim, iki veya daha fazla nokta arasında herhangi bir kablo olmadan bilgi aktarımıdır. Kablosuz iletişimimde kablolu iletişime göre kablo hattı döşeme ve bakım onarım gibi maliyetler yoktur. Bilgi alış-verişi havada yayılan elektromanyetik kablolarla gerçekleşmektedir. Herhangi bir kablo bağlantısı 
olmadığından rahatça hareket edilebilmekte, kullanıcılar için yer ve zaman kısıtlamaları ortadan kalkmaktadır [1].

Kablosuz iletişim sistemlerinin kurulumu daha hızlı ve basittir. Kablolu sistemlerin kurulamadığı ve çalışmaların tehlikeli olduğu yerlerde kablosuz iletişim ağları ile iletişim imkânı sağlanır. Dağ, tepe, nehir gibi kablolu iletişimi zor olan doğal alanlarda radyo dalgaları ile kablosuz iletişim kolaylıkla sağlanabilir. Kablosuz iletişim teknolojilerinin uygulama alanları oldukça geniştir. Kablosuz iletişim genel olarak eğitim, sağlık, ulaşım, ticaret, güvenlik, endüstri alanlarında kullanılmaktadır. Kablosuz iletişim sayesinde yakın gelecekte çoğu işin evden yürütülmesi ve böylece trafik, insan yoğunluğu ve çevre kirliliğinin azalması düşünülmektedir [2-3].

Endüstriyel bir süreçte yer alan değişkenler; akış hızı, sıvı seviye, sıcaklık, basınç, derişim gibi değerlerdir. Bir kimyasal prosesin çeşitli değişkenlerini sabit tutabilmek için kontrol sistemleri kullanılmaktadır [4-5]. S1v1 seviye kontrolü bir kimyasal proses için çok önemlidir. Bilgisayar sistemlerinin geliştirilmesi ile birlikte artan endüstriyel proseslerin bilgisayar destekli kontrolü; çalışanlar için güvenli bir çalışma ortamı, ürün kalitesindeki farklılı̆̆ın azaltılması, proses parametrelerinin anlık ve sürekli olarak izlenmesi ve proseste istenmeyen bir durum oluştuğunda anında müdahale edebilmek açısından büyük fayda sağlamaktadır. Ayrıca proseslerin tasarım, kurulum ve üretim maliyetleri göz önüne alındığında, proseslerin ve çalışanların güvenliğini sağlamak için üretim sırasında değişiklik gösteren, farklı birçok proses parametresinin on-line bilgisayarlarla sürekli olarak ölçüm ve kablosuz kontrol edilmesi son derece önemlidir [6-7].

\section{SISTEM TANIMLAMA (SYSTEM IDENTIFICATION)}

Sistem tanımlama, proses kontrol çalışmalarının başarısını etkileyen oldukça önemli bir işlemdir. Dinamik bir sistemde gerçekleştirilen deneysel çalışmalarda elde edilen veriler kullanılarak sistemi en iyi şekilde tanımlayan matematiksel model belirlenmeye çalışılır. Sistem tanımlama bir prosesten elde edilen girişçıkış değişkenleri verilerinin öngörülen modele uygunluğunun araştırıldığı bir yöntemdir. Sisteme herhangi bir etki (basamak, PRBS, kare dalga gibi...) verilmesi ve belli zaman aralıklarında elde edilen çıkış değişkeni verileri kullanılarak prosesin dinamik davranışını veren matematiksel model parametreleri bulunur [8].

Bir sistem için Eş.1'deki gibi genel bir model oluşturulabilir.

$$
s(t)=\frac{D(t)}{A}+\frac{D}{A} v(t)+\frac{C}{A} e(t)
$$

Tüm yük elemanlarının sistemin genel çıktı ve girdi değişkenlerini içeren modele ilavesi ile belirlenen yeni modele ARMAX denir. Toplam ARMAX modeli Eş.2'de gösterilmiştir.

$$
y(t)=\frac{B}{A} u(t-1)+\frac{D(t)}{A}+\frac{D}{A} v(t)+\frac{C}{A} e(t)
$$

\section{Eş.2'de gösterilen tüm yük ifadeleri aşağıda özetlenirse;}

i) Sabit offset oluşumu prosesin doğasından veya algılayıcısı olan cihazlardan kaynaklanabilir.

ii) $v(t)$ ölçülebilen fakat ileri beslemeli kontrol sistemi ile kontrol edilemeyen bir sinyal olabilir.

iii) e(t) sistemin ölçülebilen çıktısını etkileyen bir gelişigüzel yüktür. 
Sadece (iii) göz önüne alınırsa,

$y(t)=\frac{B}{A} u(t-1)+\frac{C}{A} e(t)$

Eş.3’te verilen modele CARMA veya ARMAX modeli denir. Eğer modele offset eklenirse;

$$
A y(t)=B u(t-1)+C e(t)+d
$$

Bu modele ise genelleştirilmiş ARMAX veya CARMA denir. Bazı durumlarda Eş.4'ü integre etmekle ARIMAX ya da CARIMA elde edilir [8].

$$
y(t)=\frac{B}{A} u(t-1)+\frac{C}{\Delta A} e(t)
$$

Gelişigüzel ikili sinyal etkileri (PRBS) parametre tahmini için test sinyali olarak kullanılır. Bu konu genel olarak rastgele proses etkileri için deneysel tasarım olarak bilinmektedir. Rastgele proses etkileri sıklık temelinde, iletim fonksiyonları için yapılan çözümleri basitleştirmek için seçilir.

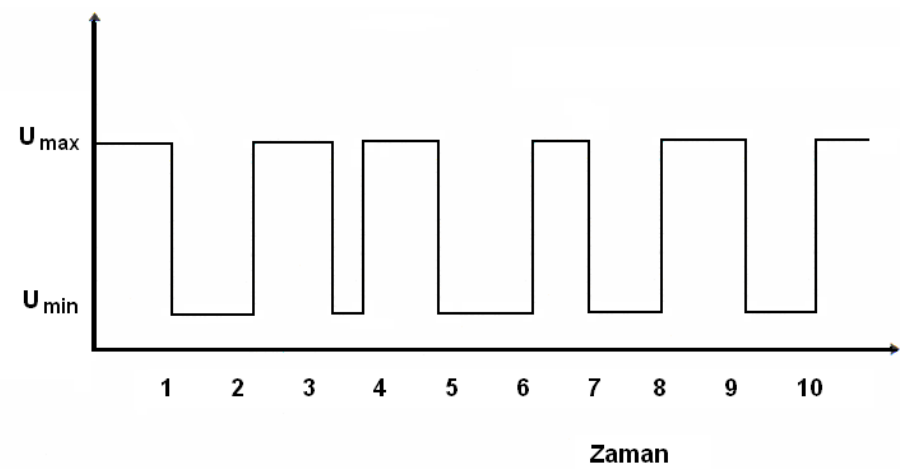

Şekil 1. PRBS sinyalinin gösterimi (Display of PRBS signal)

Şekil 1'de gösteriminin verildiği PRBS sinyallerinin prosese verdiği değişimler genelde, proses işletim şartları içerisinde olmalıdır. PRBS sinyalleri ile parametre tahmini için genelde Bierman algoritması kullanılır. Bunun için her PRBS sinyali değiştiğinde Bierman algoritması bir set parametre hesaplar. Bu parametre setleri PRBS sinyalleri değiştikçe farklı değerler alır. PRBS sinyalleri, prosesi belli işletim şartlarında taradığından bulunan parametreler de tüm işletim şartlan için geçerlidir. Bu nedenle kontrol amacıyla parametre tahmininde en uygun değerlerin seçimi sağlanır [9].

\section{DENEY SISSTEMI (EXPERIMENTAL SYSTEM)}

Deneysel çalışmalar Cussons P3005 model Proses Kontrol Simülatöründe gerçekleştirilmiş olup, sistem ile bilgisayar arasında veri aktarımını sağlamak için wireless iletişim sistemi kurulmuştur. Kablosuz ölçüm ve kontrol amacıyla proses kontrol simulatöründe birtakım modifikasyonlar yapılmıştır. Bu amaçla bilgisayar ve sistem arasında iletişimi sağlayabilmek adına sisteme ve içeriye veri aktarımını sağlayan iki adet anten koyulmuştur. Ayrıca proseste ayar değişkenleri olarak belirlenen; sıvı seviye kontrol vanası, 1sıtıcı, basınç kontrol vanası kalibre edilmiş ve bunların çıkışları modüllere bağlanmıştır. Bu modüller iki anten arasındaki 
aktarılan verileri bünyesinde bulundurmaktadır. Proses kontrol simülatörünün diğer bir birimi ise elektronik devrelerin bulunduğu panodur. Bu panoda sıcaklık, sıvı seviye kontrol ve akış hızının kontrolü ve ölçümü yapılabilmektedir. Kablosuz kontrol ve ölçüm için yeni ekipmanlar eklenmiştir.

Şekil 2'de kablosuz kontrol amaciyla geliştirilen proses kontrol simülatörü, Şekil 3'de ise sistem ve bilgisayar arasında kablosuz veri aktarımını sağlayan anten ve modüller verilmiştir.

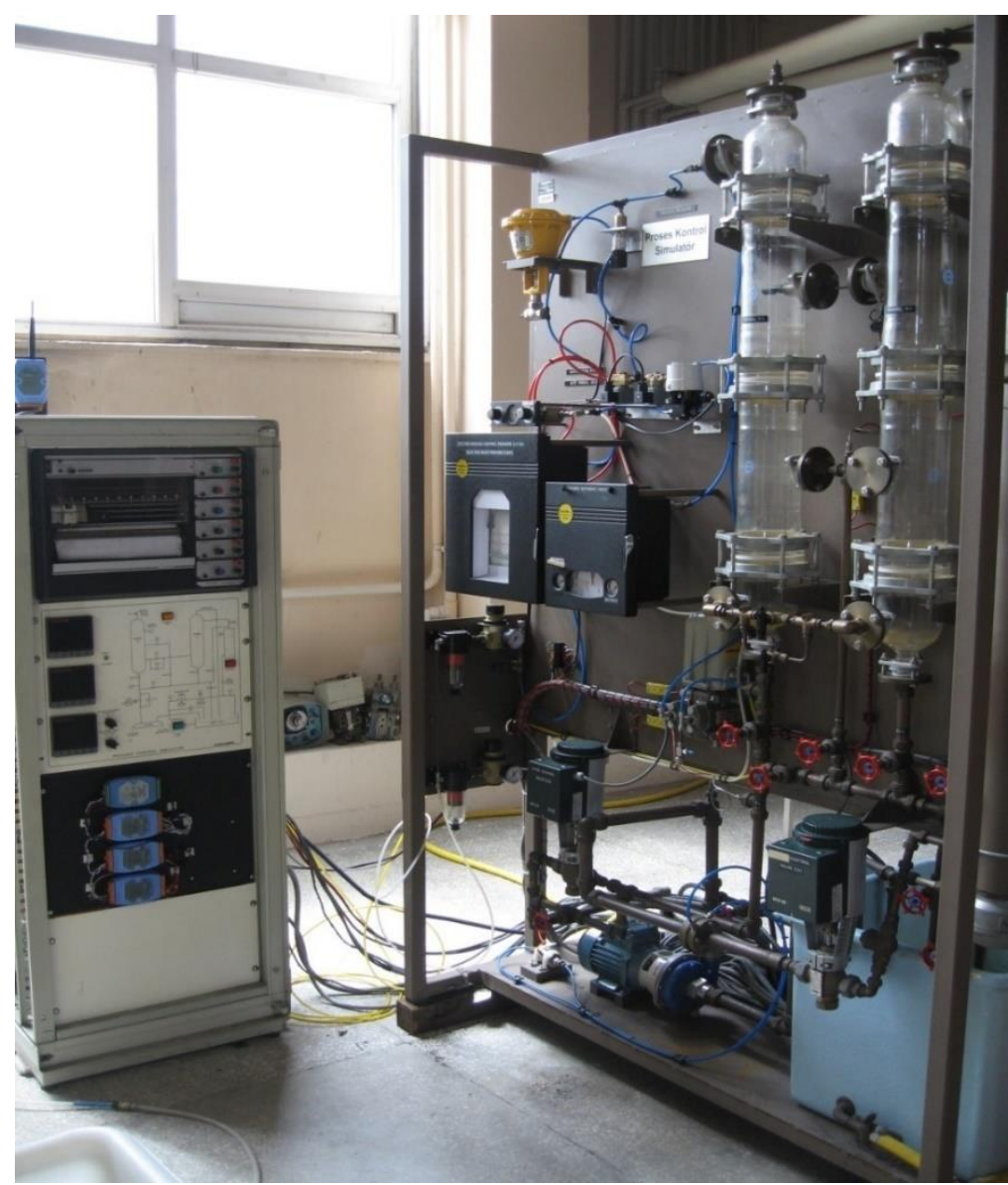

Şekil 2. Kablosuz kontrol amacı ile geliștirilen proses kontrol simülatörü ( Process control simulator developed with wireless control purpose)

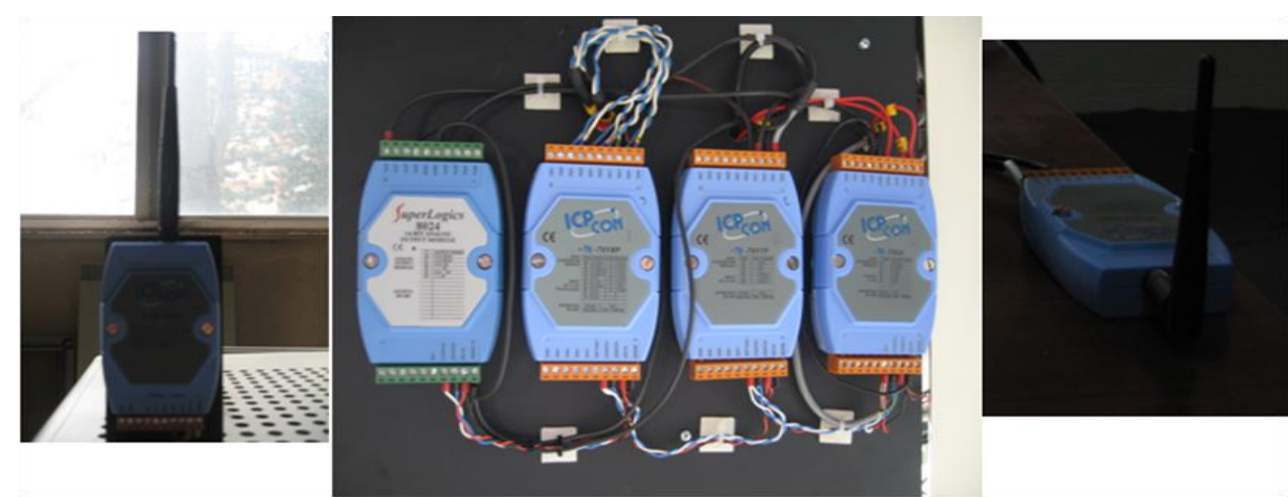

Şekil 3. Kablosuz veri aktarımını sağlayan antenler ve modüller (Antennas and modules for wireless data transmissions) 
Proses kontrol simülatörünün sıvı seviye deneyi için seviye kontrol döngüsü ve proses akım şeması Şekil 4 'te gösterilmiştir. Sisteme beslenen suyun muhafaza edildiği bir adet tank, sisteme sivıyı besleyen elektrik ile çalışan bir adet pompa, şebeke suyu ile soğutmanın yapıldığı ceketli soğutucu, sistemde suyun tutulduğu iki adet cam tank, elektrik ile çalışan bir adet sıvı seviye kontrol vanası (CV1) ve akış hızı kontrol vanası (CV2), akış hızını ölçen bir adet orifismetre, diferansiyel basınç farkını sıvı seviyesine çeviren bir adet transmitter, sıvının taşmasını önlemek amacıyla pompanın otomatik olarak kapanmasını sağlayan sigorta, pnömatik basınç kontrol edici indikatörü, pnömatik basınç kaydedici, pnömatik olarak çalışan basınç kontrol vanası, sisteme kompresörden gelen basınçlı havayı istenilen basınç değerindeki havayı ileten iki adet regülator bulunmaktadır. Ayrıca sistemde dört farklı deney düzeneğini oluşturabilmek için elle ayarlanan vanalar bulunmaktadır [10].

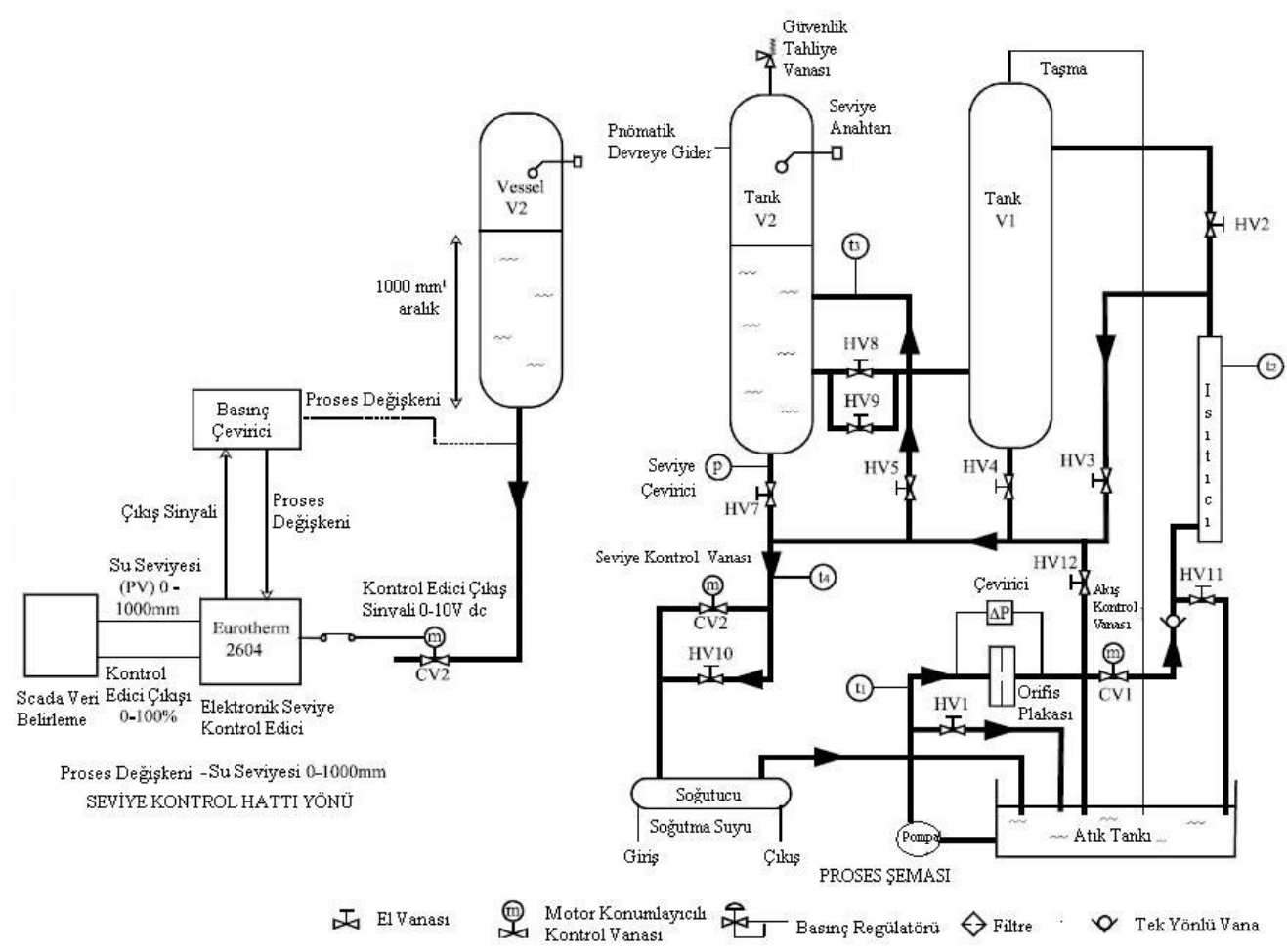

Şekil 4. Sivı seviye deneyi için seviye kontrol döngüsü ve proses akım şeması (Level control cycle and process flow diagram for liquid level test)

\section{SONUÇLAR (RESULTS)}

Proses kontrol simülatöründe dinamik hal deneyeleri basamak etki, PRBS ve kare dalga etki verilerek yapılmıştır. Bu etkiler sonucunda elde edilen çıkış değişkeni verileri ile sistemin model parametrelerini belirlenmiştir. Şekil 5'te dinamik deneyler için kullanılan MATLAB/Simulink programının şematik şekli verilmiştir. Burada sistemin kablosuz veya kablolu bir şekilde kontrolunun yapılabilmesi için bir adet kablosuz açma/kapama düğmesi, proses parametrelerinin sayısal ve grafiksel olarak gösterildiği bloklar, hata sinyallerinin depolandığı ve bir önceki sinyalle devam et komutunun yazılı olduğu bloklar bulunmaktadır. 
Dinamik hal deneyleri basamak etki, PRBS ve kare dalga etki verilerek yapılmıștır. PRBS etkinin deneylerin yapılabilmesi için sisteme PRBS algoritmasının yazıldığı bir blok eklenmiştir. Sistemin öncelikle yatışkın hale gelmesi sağlanmış, daha sonra PRBS algoritmasının yazıldığg blok devreye alınarak deneye devam edilmiştir.

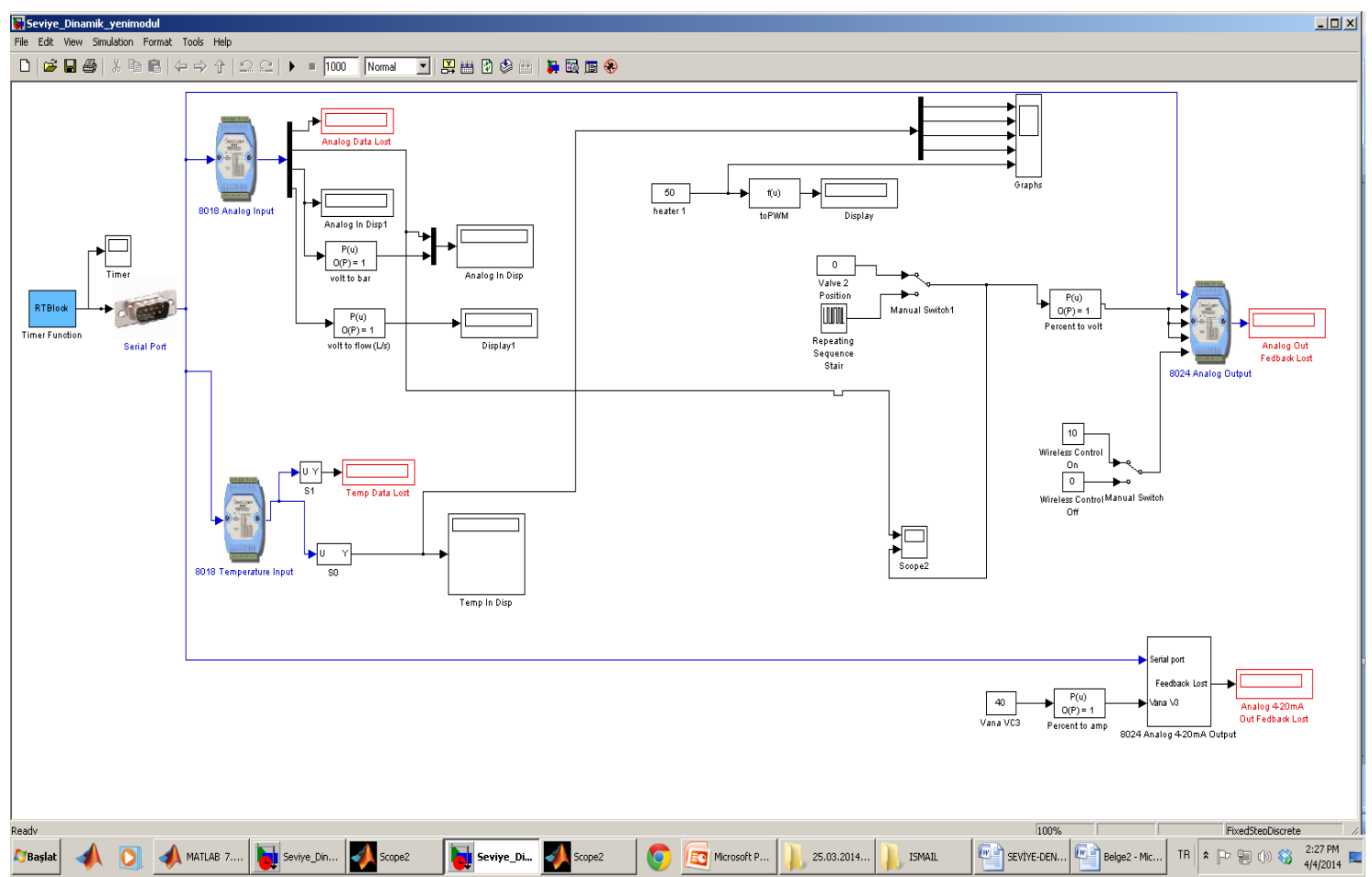

Şekil 5. Dinamik hal sıvı seviye deneyinin MATLAB/Simulink blok diyagramı (MATLAB/Simulink block diagram of the dynamic state liquid level experiment)

\subsection{Basamak etkinin verildiği dinamik hal deney sonucu (The result of dynamic state test in which the step effect is given)}

Basamak etki deneylerinde, sıvı seviye kontrol vanası açıklığına belli etkiler verilmiş daha sonra sistemin yatışkın hale gelmesi beklenmiştir. Sistem öncelikle \% 10 vana açıklığında çalıştırılarak sistemin yatışkın hale gelmesi beklenmiştir. Seviye kontrol vanasına pozitif etki verilerek (\%10-65) sıvı seviyedeki değişim gözlenmiştir. Şekil 6'da basmak etki altında sıvı seviye vana açıklığının zamanla değişimi, Şekil 7'de ise bu etki altında sıvı seviyesinin dinamik davranışı verilmiștir. 


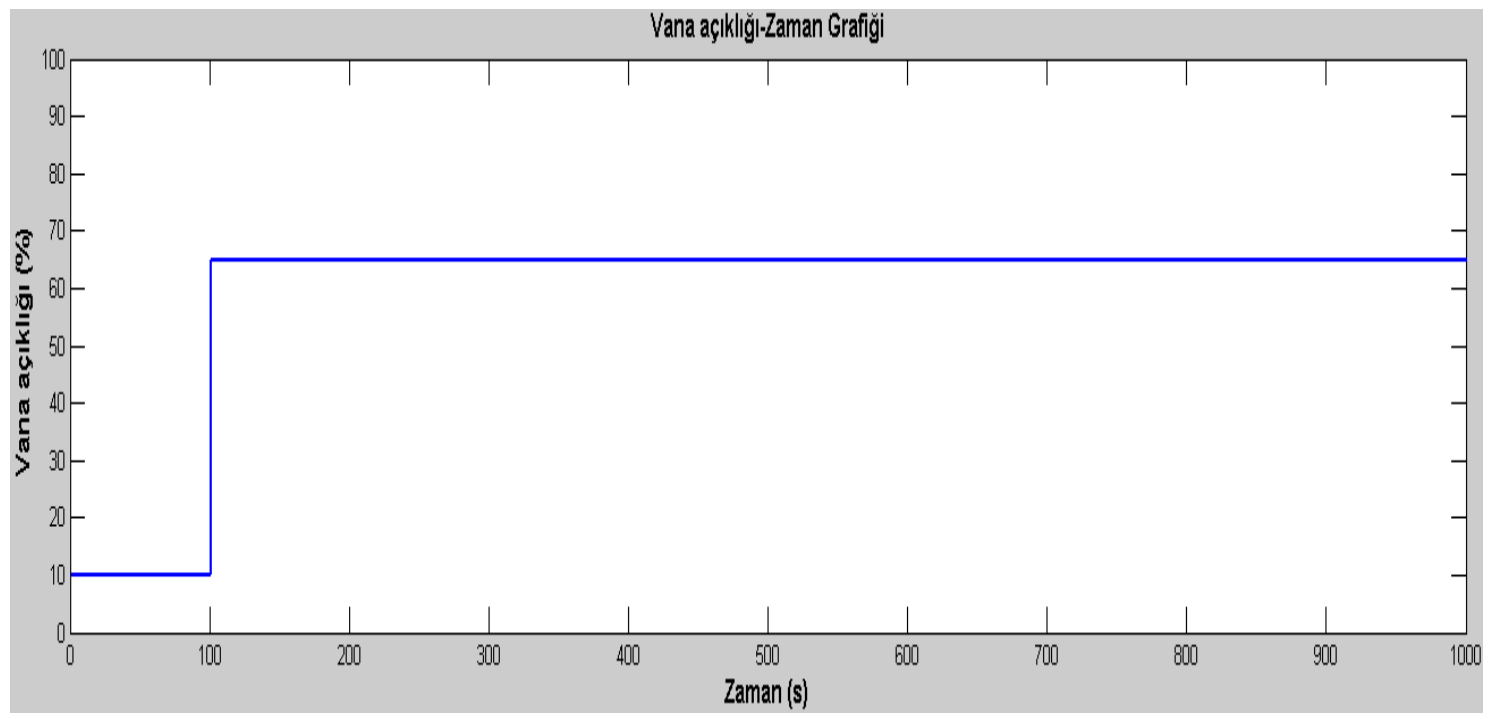

Şekil 6. Basamak etki altında sıvı seviye vana açılı̆̆ıııın (\%) zamanla değiş̧im grafiği (Fluctuation of liquid level valve opening (\%) under step effect over time)

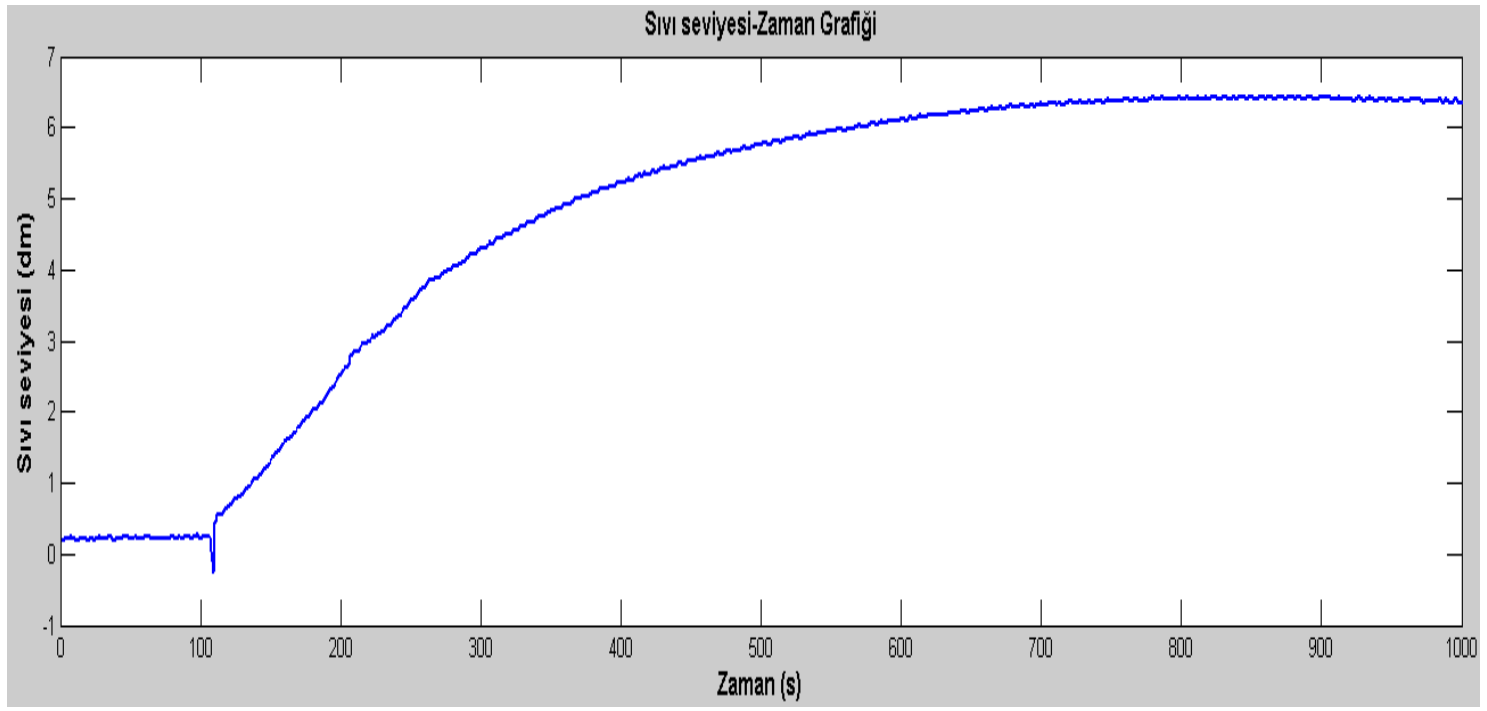

Şekil 7. Basamak etki altında sıvı seviyesinin zamanla değişim grafiği (Fluctuation of liquid level with time under the influence of step)

\subsection{PRBS etkinin verildiği dinamik hal deney sonucu (The result of dynamic state test in which the PRBS effect is given)}

PRBS etki verilerek yapılan deneyde ise sistem model parametrelerini hesaplayabilmek için sisteme sinyaller verilmiştir. Deneyde sıvı seviye vana açıklığ $\% 10$ değerinde tutularak 100s çalışıldıktan sonra sıvı seviyesi yatışkın hale getirilmiştir. Daha sonra Simulink programında bulunan PRBS bloku yardımıyla Sıvı seviye vana açıklığına $\% 10$ ve $\% 65$ olmak üzere gelişigüzel ikili etkiler verilmiştir. Şekil 8'de PRBS etki altında sıvı seviye vana açıklığının zamanla değişimi, Şekil 9'da ise bu etki altında sıvı seviyesinin dinamik davranışı verilmiştir. 


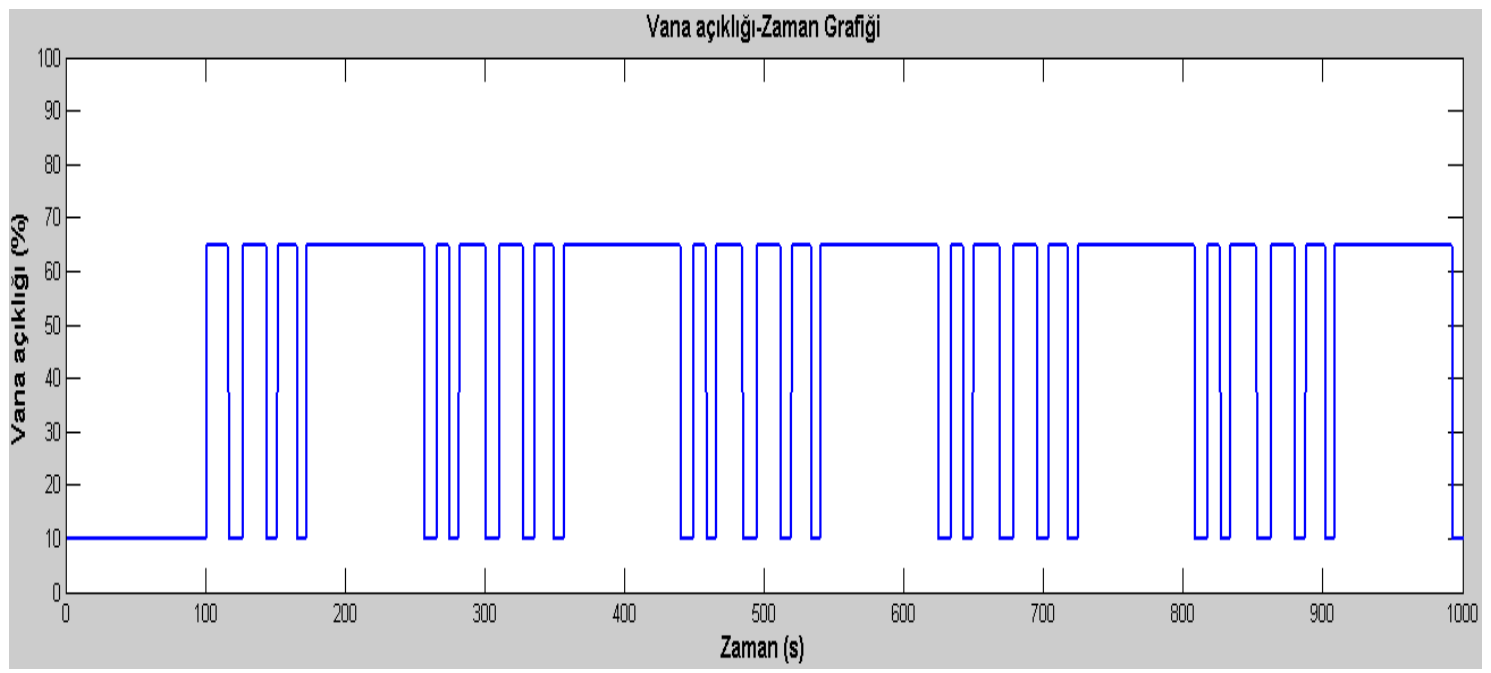

Şekil 8. PRBS etki altında sıvı seviye vana açıklığının zamanla değişim grafiği (Fluctuation of liquid level valve opening (\%) under PRBS effect over time)

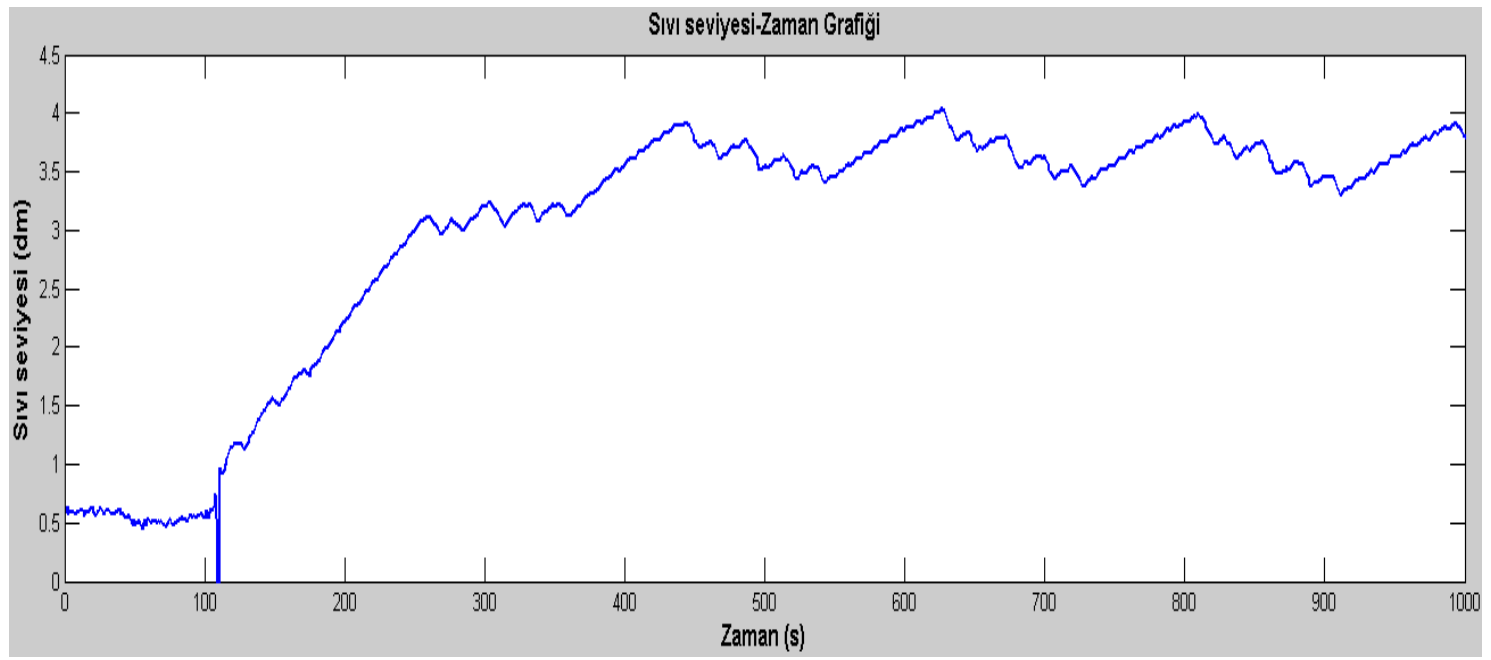

Şekil 9. PRBS etki altında sıvı seviyesinin zamanla değişim grafiği (Fluctuation of liquid level with time under the influence of PRBS)

\subsection{Kare dalga etkinin verildiği dinamik hal deney sonucu (The result of dynamic state test in which the Square wave effect is given)}

Sistem 100s yatışkın halde işletildikten sonra sıvı seviye vana açıklığına 75 s'lik periyotlarda pozitif ve negatif etkiler verilerek sıvı seviyesinin değişimi gözlenmiştir. Şekil 10'da kare dalga etki altında sıv1 seviye vana açıklığının zamanla değişimi, Şekil 11'de ise bu etki altında sıvı seviyesinin dinamik davranışı verilmiştir. 


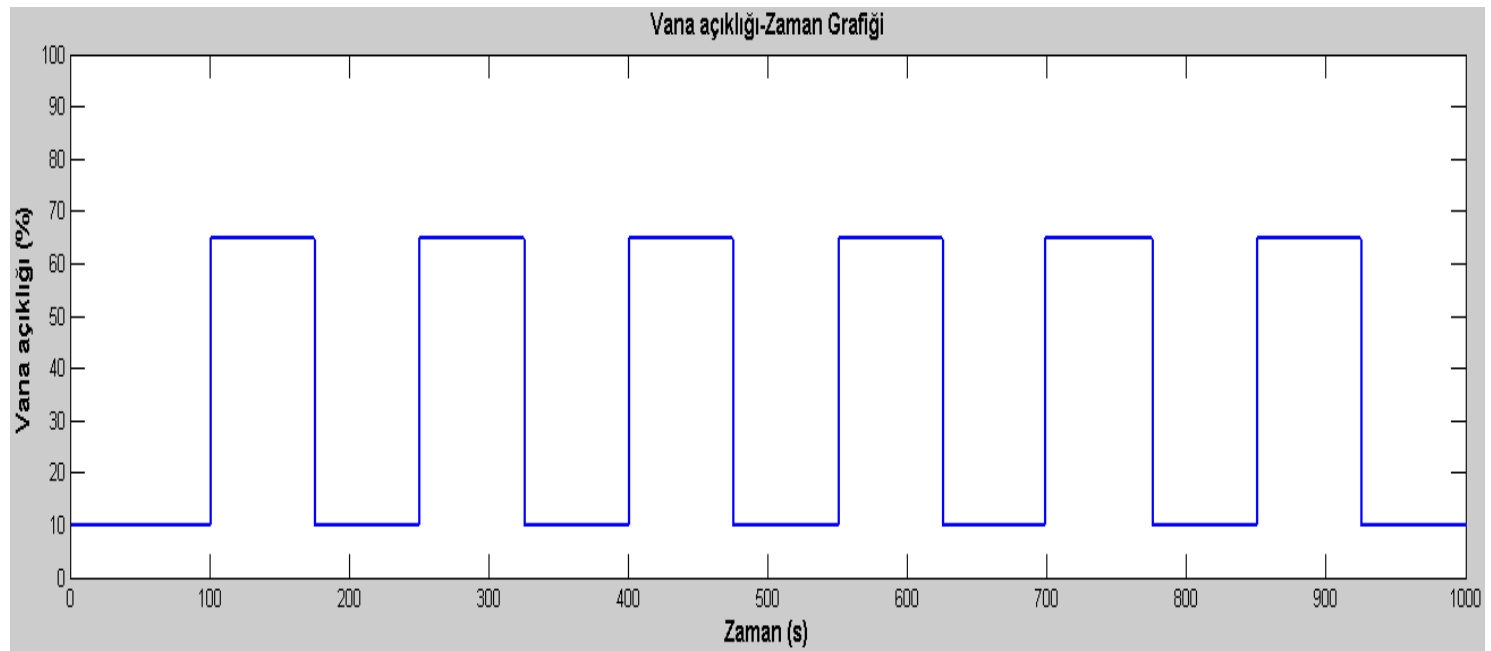

Şekil 10. Kare dalga etkisi altında sıvı seviye vana açıklı̆̆ının zamanla değişim grafiği (Fluctuation of liquid level valve opening (\%) under square wave effect over time)

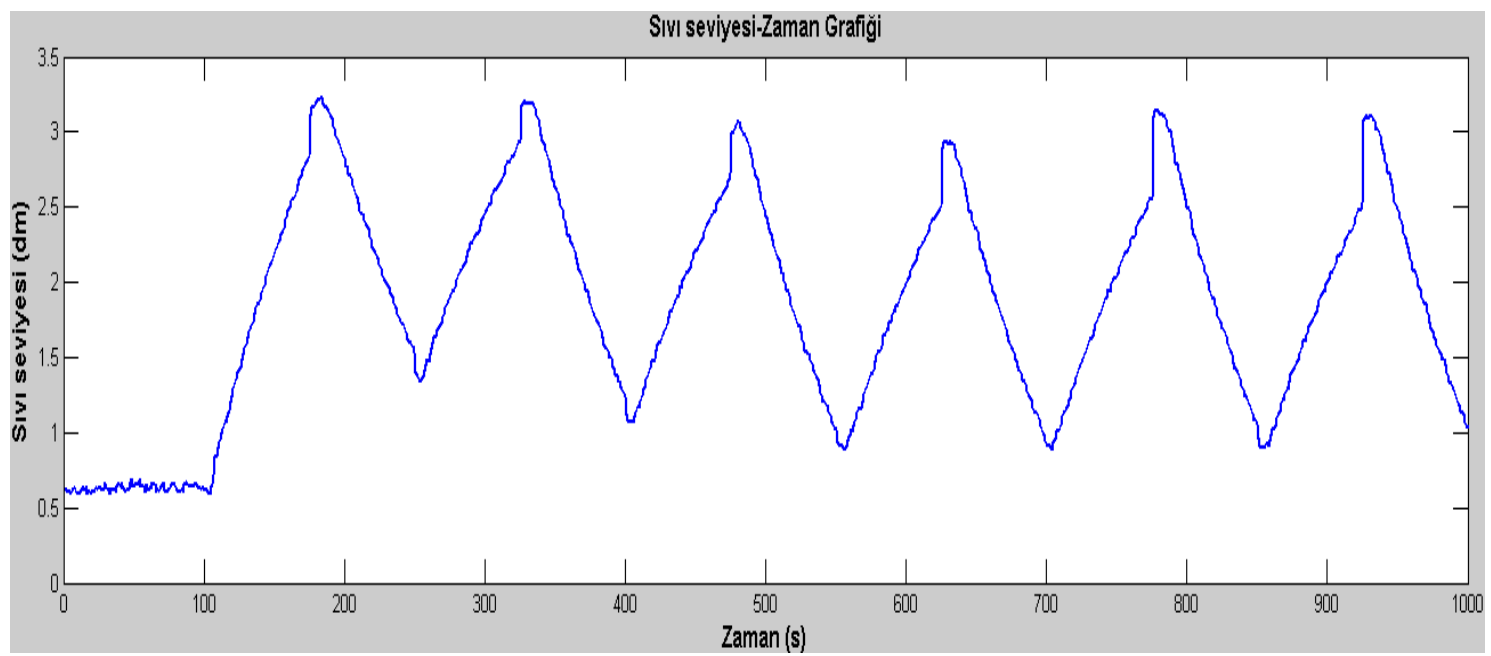

Şekil 11. Kare dalga etkisi altında sıvı seviyesinin zamanla değişim grafiği (Fluctuation of liquid level with time under the influence of square wave)

\subsection{Sistem Tanımlama Sonuçları (System Identification Results)}

Sistem tanımlama için sıvı seviye kontrol vanasına PRBS, kare dalga ve basamak etkiler verilerek sıvı seviyesinin zamanla değişimi gözlenmiştir. Böylelikle birinci mertebeden ölü zamanlı ARIMAX model eşitlikleri belirlenmiştir. Sistem tanımlama model katsayılarının belirlenmesinde 'MATLAB System identification toolbox' kullanılmıştır. Basamak, PRBS, kare dalga etkinin verildiği ARIMAX model ile deneysel verilerin kıyaslanması sırasıyla Şekil 12, Şekil 13 ve Şekil 14’te verilmiştir. 


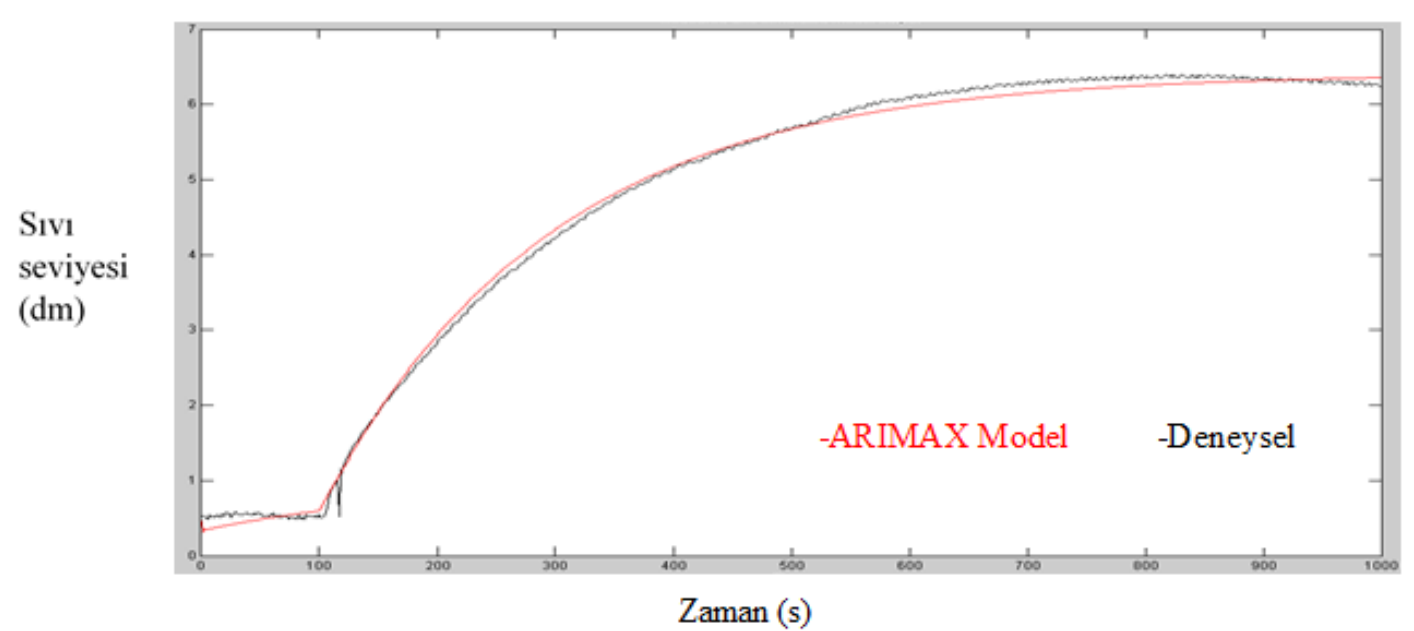

Şekil 12. Basamak etkinin verildiği ARIMAX model ile deneysel verilerin karşılaştırılması (Comparison of experimental datas with ARIMAX model influnce step effect)

Basamak etki sonucu belirlenen model Eş.6'da verilmiştir.

$\mathrm{y}(\mathrm{t})-0.715 \mathrm{y}(\mathrm{t}-1)+0.277 \mathrm{y}(\mathrm{t}-2)=0.00021 \mathrm{u}(\mathrm{t})-0.0088 \mathrm{u}(\mathrm{t}-1)-0.00047 \mathrm{u}(\mathrm{t}-2)+\mathrm{e}(\mathrm{t})-0.6289 \mathrm{e}(\mathrm{t}-1)-$ $0.1386 \mathrm{e}(\mathrm{t}-2)$

Basamak etki sonucunda sistem tanımlama yöntemiyle elde edilen bu model sonuçları ile deneysel dinamik sonuçlar karşılaştırıldığında $6 \mathrm{dm}$ set noktası için elde edilen verilerin birbiriyle uyumlu olduğu görülmüştür.

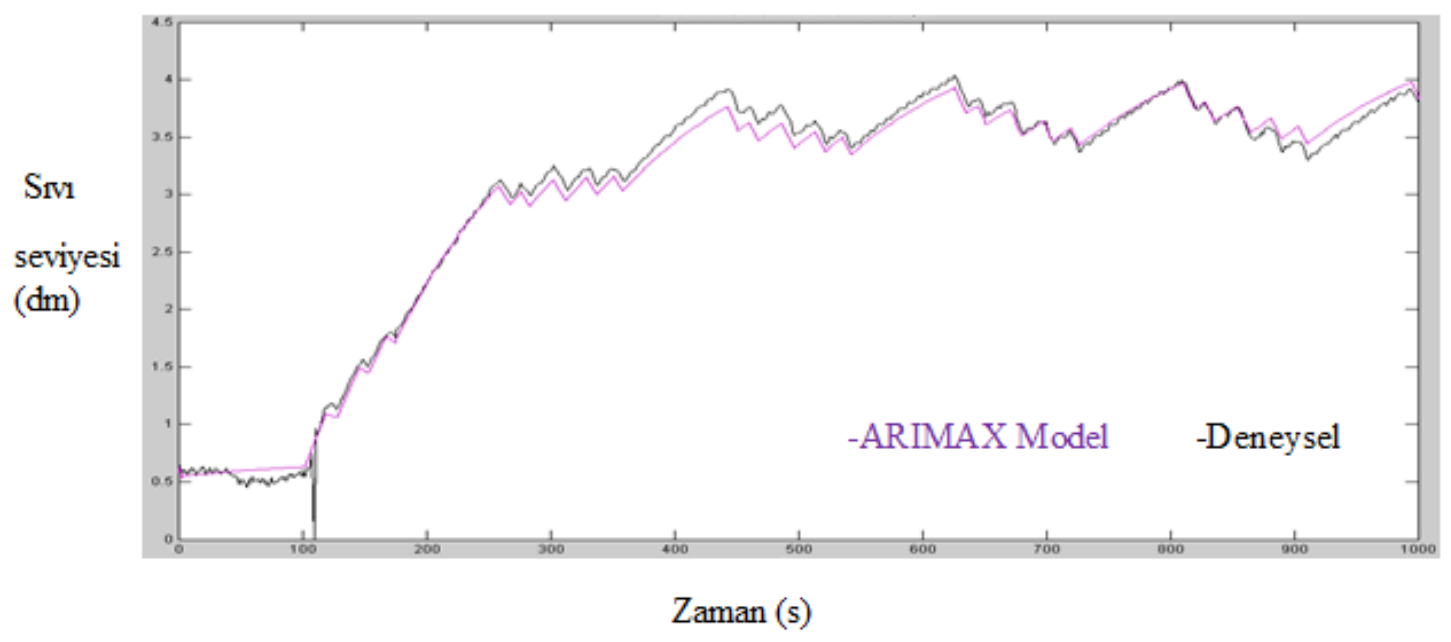

Şekil 13. PRBS etkinin verildiği ARIMAX model ile deneysel verilerin karşılaştırılması (Comparison of experimental datas with ARIMAX model influncePRBS effect)

PRBS etki sonucu belirlenen model Eş.7'de verilmiştir.

$\mathrm{y}(\mathrm{t})-0.783 \mathrm{y}(\mathrm{t}-1)+0.210 \mathrm{y}(\mathrm{t}-2)=0.00016 \mathrm{u}(\mathrm{t})-0.0062 \mathrm{u}(\mathrm{t}-1)-0.00034 \mathrm{u}(\mathrm{t}-2)+\mathrm{e}(\mathrm{t})-0.7487 \mathrm{e}(\mathrm{t}-1)-$ $0.01944 \mathrm{e}(\mathrm{t}-2)$ 


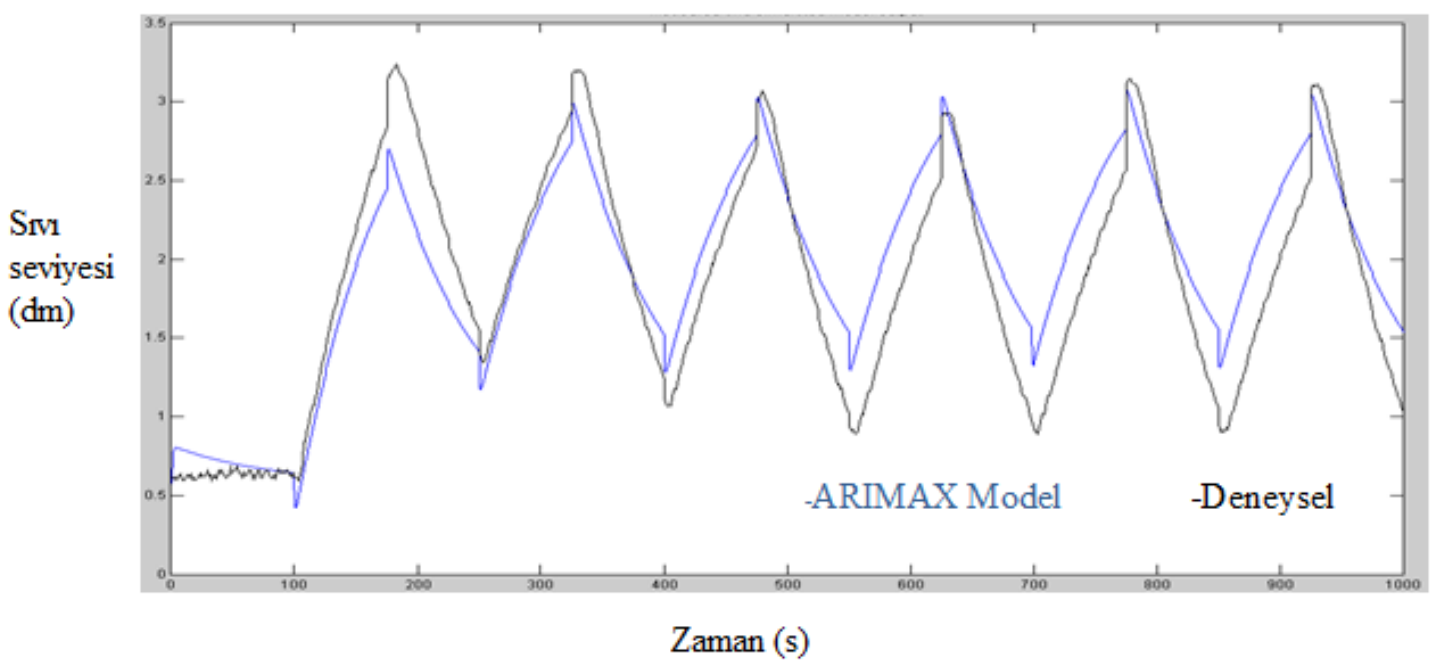

Şekil 14. Kare dalga etkinin verildiği ARIMAX model ile deneysel verilerin karşılaşstırlması (Comparison of experimental datas with ARIMAX model influnce square wave effect)

Kare dalga etki sonucu belirlenen model Eş.8'de verilmiştir.

$\mathrm{y}(\mathrm{t})-1.169 \mathrm{y}(\mathrm{t}-1)+0.886 \mathrm{y}(\mathrm{t}-2)=0.00036 \mathrm{u}(\mathrm{t})-0.0078 \mathrm{u}(\mathrm{t}-1)-0.00073 \mathrm{u}(\mathrm{t}-2)+\mathrm{e}(\mathrm{t})-0.867 \mathrm{e}(\mathrm{t}-1)-0.007 \mathrm{e}(\mathrm{t}-$ 2)

Eş.8 ve Eş.9'dan elde edilen teorik sonuçların deneysel sonuçlarla örtüştügü görülmüştür.

\section{TARTIŞMA (CONCLUSION)}

Proses kontrol simülatörü kablosuz sıvı seviye deney sistemi kullanılarak deneysel sıvı seviye çalışmaları yapılmıştır. Bu dinamik deneyler MATLAB paket programında bulunan Simulink blok diyagramı yardımıyla basamak, PRBS ve kare dalga etkileri altında gerçekleştirilmiştir. Deneysel çalışmalar sonucu elde edilen giriş değişkeni (sıvı seviye kontrol vana açıklığı) verileri ile, MATLAB paket programında bulunan 'Sistem tanımlama araç kutusu' yardımıyla teorik sıvı seviye grafikleri oluşturulmuştur. Sonuçlar kısmında basamak, PRBS ve kare dalga etkiler sonucu elde edilen proses kontrol simülatörü sistemiyle yapılan deneysel verilerle, MATLAB'ta oluşturulan teorik veriler gösterilmiştir. Çalışmalar sonucunda ARIMAX model eşitlikleri çıkarılmıştır. Sistem tanımlama yöntemiyle elde edilen bu model sonuçları ile deneysel dinamik sonuçlar karşılaştırıldığında birbiriyle uyumlu olduğu görülmüştür.

\section{SEMBOLLER (SYMBOLS)}

CV1 Flow Control Valve

CV2 Level Control Valve

CV3 Pressure Control Valve

$u(t)$ Ayarlanabilen değişken

y(t) Çıkış değişkeni 


\section{Kisaltmalar (Shortcuts)}

ARMA Auto Regressive Moving Average

ARMAX Auto Regressive Moving Average eXogenous

ARIMAX Auto Regressive Integral Moving Average eXogenous

PRBS Pseudo Random Binary Sequence

\section{KAYNAKLAR (REFERENCES)}

[1] Aldemir A., Hapoğlu H., Alpbaz M., Application of MATLAB/Simulink Program for Wireless Generalized Predictive Control, International Journal of Engineering and Innovative Technology (IJEIT), 3(12), 19-22, 2014

[2] Murari A. and Lotto L. Wireless Communication Using Detectors Located Inside Vacuum Chambers, Vacuum 72,149-155, 2004

[3] Çetinkaya S. , Durmazuçar H. H. , Zeybek Z., Hapoğlu H. , Alpbaz M.,Application of temperature control in a bacth polymerization reactor at different optimal temperature, Journal of the Faculty of Engineering and Architecture of Gazi University, 28, 2, 383-392, 2013.

[4] Donatas L., Rimvydas S.,; Vytautas G., Adaptive set-point control system for microbial cultivation processes, Nonlinear analysis-modelling and control, 21(2),153-165, 2016

[5] Martin D., Klavco F. J., Janecek F., Kvasnica M. Optimal Control of a Laboratory Binary Distillation Column via Regionless Explicit MPC, Computers and Chemical Engineering, 96 139-148, 2017.

[6] Cancelier A., Claumann C. A., Bolzan A., Machado R.A.F., Predictive control of a batch polymerization system using a feedforward neural network with online adaptation by genetic algorithm , Brazilian journal of chemical engineering ,33 (1), 177-190, 2016

[7] Alpbaz M.,Hapoğlu H. ve Akay B., 'Proses Kontrol', Gazi Kitabevi, Ankara, 2011.

[8] Bayram, İ., 'İleri Kontrol Yöntemleriyle Kablosuz Sıvı Seviye Kontrolü', Doktora Tezi, Ankara Üniversitesi, Fen Bilimleri Enstitüsü, 2015.

[9] Altınten, A., 'Generalized Predictive Control Applied to a pH Neutralization Process', Computers and Chemical Engineering', 31, 1199-1204, 2007.

[10] Cara, D., 'Wireless Networks for Industrial Automation', ISA-The Instrumentation, Systems and Automatin Society, 2008. 